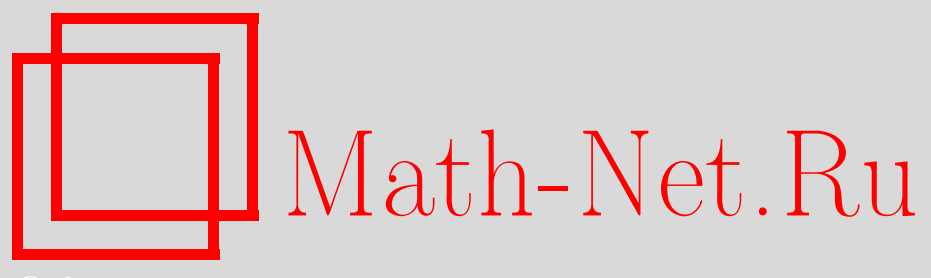

Ф. Г. Авхадиев, В. А. Ботвинник, С. К. Водопьянов, М. Вуоринен, В. М. Гольдштейн, В. В. Горяйнов, А. А. Григорьян, В. Н. Дубинин, И. В. Журавлев, В. А. Зорич, В. М. Кесельман, А. А. Клячин, В. А. Клячин, Т. Г. Латфуллин, А. В. Лобода, А. Г. Лосев, О. Мартио, В. И. Пелих, С. И. Пинчук, Ю. Г. Решетняк, А. С. Романов, А. Г. Сергеев, В. Г. Ткачев, Е. М. Чирка, Владимир Михайлович Миклюков (некролог), УМН, 2014, том 69, выпуск 3, 173-176

DOI: https://doi.org/10.4213/rm9595

Использование Общероссийского математического портала Math-Net.Ru подразумевает, что вы прочитали и согласны с пользовательским соглашением http://www . mathnet.ru/rus/agreement

Параметры загрузки:

IP : 52.6 .47 .48

26 апреля 2023 г., $14: 23: 37$

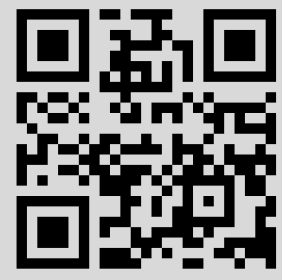




\section{Владимир Михайлович Миклюков}

1 октября 2013 г. ушел из жизни Владимир Михайлович Миклюков - выдающийся математик, крупный специалист в области математического анализа и теории функций, создавший Волгоградскую научную школу геометрического нелинейного анализа, получившую мировое признание.

Владимир Михайлович Миклюков родился 8 января 1944 г. в селе Раскатиха Коптеловского района Свердловской области. В 1968 г. после окончания физико-математического факультета Донецкого государственного университета В. М. Миклюков поступил в аспирантуру Донецкого вычислительного центра АН УССР, где в 1970 г. под руководством чл.-корр. АН УССР Г. Д. Суворова защитил кандидатскую диссертацию по теории квазиконформных отображений в пространстве. Центральным результатом рабо-

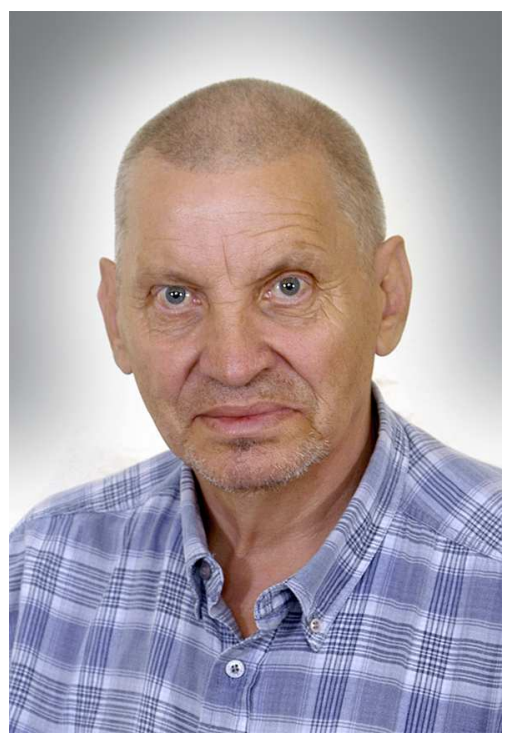
ты является теорема о конечности угловых граничных значений монотонных квазиконформных отображений класса $W_{p}^{1}, n-1<p \leqslant n$, вне исключительного множества нулевой $\alpha$-емкости.

С 1970 по 1973 г., в период работы В. М. Миклюкова в Донецком вычислительном центре АН УССР, в круг его научных исследований входили теоремы существования квазиконформных отображений с неограниченными характеристиками, проблемы устранения особенностей и существования угловых граничных значений отображений с обобщенными производными, вопросы устойчивости квазиконформных отображений шара на шар.

В дальнейшем, продолжив свою работу в Тюменском госуниверситете, В. М. Миклюков заинтересовался теорией нелинейных (квазилинейных) дифференциальных уравнений второго порядка эллиптического типа, в частности классическим их представителем, уравнением минимальной поверхности. В.М. Миклюков привлек развитые им методы теории квазиконформных отображений в новую для себя область исследований. В результате усовершенствованная емкостная и модульная техника позволила ему не только решить целый ряд важных и трудных задач качественной теории квазилинейных дифференциальных уравнений эллиптического типа, но и разработать новые емкостные методы нелинейного анализа.

DOI: $10.4213 / \mathrm{rm} 9595$ 
В 1981 г. в Национальной академии наук Украины (Киев) В. М. Миклюковым была защищена докторская диссертация, посвященная емкостным методам в задачах нелинейного анализа. Рассматривались задачи качественного исследования поведения решений и субрешений введенного В. М. Миклюковым широкого класса квазилинейных уравнений вида $\sum_{i=1}^{n} \frac{d}{d x_{i}} A_{i}(x, \nabla f)=0$ с оператором $A$, подчиненным дополнительным структурным условиям, охватывающим условия как сильной, так и слабой нелинейности. (Суб)решения данного класса уравнений включают в себя, в частности, уравнение минимальной поверхности, $p$-(суб)гармонические функции, а также тесно связаны с отображениями с ограниченным искажением.

Оригинальность метода изучения уравнений типа минимальной поверхности заключалась в том, что вместо традиционного использования конформных координат, эффективных лишь в двумерном случае, применялись конформные инварианты конформный модуль либо конформная емкость, причем В.М. Миклюковым была развита тонкая техника получения оценок указанных инвариантов на поверхностях, являющихся графиками (суб)решений уравнения типа минимальной поверхности.

Центральные результаты работы касаются асимптотического или граничного поведения (суб)решений квазилинейных уравнений второго порядка эллиптического типа, рассматриваемых в метрике заданной $n$-мерной поверхности. К таким результатам относятся полученные в наиболее общей форме теорема Лиувилля, теоремы типа Фрагмена-Линделёфа, обобщенный принцип максимума, теоремы о поведении решений в окрестности изолированной особой точки, а также яркие приложения к уравнениям минимальной и типа минимальной поверхности.

Непосредственными следствиями общей теоремы Лиувилля являются классические теорема Бернштейна для минимальных поверхностей на плоскости и теорема Лиувилля для субгармонических функций. Тем самым, для класса уравнений типа минимальной поверхности был дан новый подход к доказательству теоремы Бернштейна.

В качестве приложения обобщенного принципа максимума была получена теорема о единственности решения задачи Дирихле для двумерной минимальной поверхности в неограниченной области (такая задача была поставлена И. С. С. Ниче еще в 1965 г.).

Результаты о поведении решений вблизи особой точки содержат, как частный случай, классическую теорему Берса для минимальной поверхности. Тем самым, впервые было получено доказательство этой теоремы, не использующее вспомогательных конформных координат (задача о поиске такого доказательства была поставлена Ниче в его известном обзоре теории минимальных поверхностей).

Приложениями исследований В. М. Миклюковым граничного поведения решений уравнений типа минимальной поверхности являются найденные для двумерных минимальных поверхностей и ярко отражающие их своеобразие принципиально новые аналоги классической теоремы Фату об угловых граничных значениях аналитической функции.

Теорема типа Фрагмена-Линделёфа для квазилинейных уравнений второго порядка эллиптического типа была установлена в терминах введенного В. М. Миклюковым понятия $N$-фундаментальной частоты (нашедшего ныне применение для широкого класса метрических многообразий) при самых общих предположениях относительно области, что явилось новым даже в случае классической теоремы Фрагмена-Линделёфа для гармонических функций на плоскости. 
На основе теоремы типа Фрагмена-Линделёфа был получен общий результат, примыкающий к решению классической задачи Данжуа о числе различных асимптотических мест целой аналитической функции на плоскости и устанавливающий взаимосвязь между скоростью роста целого субрешения указанного выше уравнения и числом неограниченных компонент связности множества положительности рассматриваемого субрешения. Следствиями указанного результата являются классические в теории аналитических функций теоремы Альфорса и Вимана. Кроме того, опираясь на связи (найденные Ю. Г. Решетняком) между нелинейными уравнениями эллиптического типа и пространственными отображениями с ограниченным искажением, В. М. Миклюков распространил на класс таких отображений рассмотренные выше теоремы Фрагмена-Линделёфа, Альфорса и Вимана.

В 1981 г. В. М. Миклюков был приглашен в только что открывшийся Волгоградский госуниверситет возглавить кафедру математического анализа и теории функций, единственную в то время в университете кафедру математики. В связи с этим на плечи В. М. Миклюкова легла очень ответственная и тяжелая работа по организации всей математической деятельности не только на руководимой им кафедре, но и во всем Волгоградском университете, в частности организация разработки и чтения многих математических курсов, поиск и приглашение на работу талантливых ученых, обучение новой смены молодых математиков.

Ограниченный размер данного текста позволяет лишь очень кратко описать тематику далеко не всех исследований, которые проводил В. М. Миклюков (вместе со своими учениками), работая в Волгоградском университете, и в результате которых были получены существенные продвижения и новые глубокие результаты:

- асимптотическое поведение решений нелинейных уравнений эллиптического типа: вопросы существования и асимптотические свойства целых (суб)решений для различных классов квазилинейных уравнений эллиптического типа, в частности, уравнений типа минимальных поверхностей (теоремы типа Бернштейна и Лиувилля), теоремы типа Фрагмена-Линделёфа для дифференциальных форм с конечным или бесконечным числом асимптотических трактов и приложения к топологии минимальных подмногообразий, а также принцип максимума, неравенство Гарнака и принцип Сен-Венана для производных решений указанных уравнений в неограниченных областях;

- геометрия в целом минимальных и максимальных поверхностей в пространстве Минковского, а также поверхностей с квазиконформным гауссовым отображением; оценки времени существования минимальных трубок и лент нулевой средней кривизны в евклидовом пространстве и в пространстве Минковского; вопросы устойчивости таких поверхностей при малых деформациях, связи между точками ветвления и лоренцево инвариантными характеристиками поверхностей нулевой средней кривизны;

- проблема конформного типа поверхности и развитие теории простых концов поверхностей нулевой средней кривизны в евклидовом и псевдоевклидовом пространствах, в том числе для локально липшицевых поверхностей; оценки модуля и емкости конденсаторов на поверхности с приложением к теоремам типа Альфорса и Варшавского о конформном отображении для нерегулярных поверхностей в евклидовом пространстве, применение изопериметрических методов в принципе Фрагмена-Линделёфа для квазирегулярных отображений многообразий и обобщение теоремы Вимана для квазирегулярных отображений многообразий.

В последние годы работы В. М. Миклюков распространил результаты об асимптотическом поведении решений нелинейных уравнений эллиптического типа на случай 
почти решений эллиптических уравнений и систем. Немаловажное место в последних исследованиях В. М. Миклюкова занимало углубление им классических вопросов анализа, таких как теоремы о неявных функциях, существование полного дифференциала, неравенство Гарнака для положительных монотонных по Лебегу почти $A$-решений квазилинейных уравнений.

Общее количество научных и учебно-методических работ В. М. Миклюкова составляет более 300 публикаций. Среди них 6 монографий, более 60 научных работ в ведущих отечественных и зарубежных математических журналах. Под редакцией профессора В. М. Миклюкова выпущено 5 изданий научного сборника "Записки семинара “Сверхмедленные процессы'”. В. М. Миклюков являлся руководителем двух научных грантов РФФИ (1995-1996, 1997-1998), соисполнителем проекта INTAS (1999-2002).

В. М. Миклюков неоднократно выезжал приглашенным лектором на научные семинары в Хельсинкский университет, участвовал в международных научных конференциях, периодически выступал в качестве приглашенного лектора с пленарными и секционными докладами на многих международных и всероссийских конференциях. В 1998-2000 гг. В. М. Миклюков работал в должности приглашенного профессора в Университете Бригама Янга (Юта, США).

В течение многих лет В. М. Миклюков являлся руководителем научного семинара "Геометрический анализ" и созданной им лаборатории "Сверхмедленные процессы", в работе которой принимали участие не только математики, но и представители других наук. Под его научным руководством защищено 13 кандидатских диссертаций. Пятеро из его учеников впоследствии стали докторами наук.

Указом Президента Российской Федерации от 14 февраля 2009 г. В. М. Миклюкову было присвоено почетное звание "Заслуженный деятель науки Российской Федерации".

Владимир Михайлович был высоким профессионалом своего дела, талантливым руководителем, всегда щедро делился с учениками и просто заинтересованными математиками своими новыми идеями и находками. Его отличали неизменные внимание и уважение к людям, к их проблемам, безупречная честность и принципиальность в своей работе, неподдельный интерес ко всему новому в науке и жизни.

Друзья и коллеги Владимира Михайловича Миклюкова, вся российская математика понесли с его кончиной невосполнимую утрату.

Ф.Г. Авхадиев, В.А. Ботвинник, С.К. Водопьянов, М. Вуоринен, В.М. Голъдитейн, В.В. Горяйнов, А.А. Григоръян, В.Н. Дубинин, И. В. Журавлев, В.А. Зорич, В.М. Кесельман, А.А. Клячин, В.А. Клячин, Т. Г. Латфуллин, А.В. Лобода, А. Г. Лосев, О. Мартио, В.И. Пелих, С.И. Пинчук, Ю.Г. Решетняк, А.С. Романов, А.Г. Сергеев, В.Г. Ткачев, Е. М. Чирка 